\title{
Topographic position modulates the mycorrhizal response of oak trees to interannual rainfall variability
}

\author{
José I. Querejeta, ${ }^{1,2,5}$ Louise M. Egerton-Warburton, ${ }^{1,3,4}$ And Michael F. Allen ${ }^{1}$ \\ ${ }^{1}$ Center for Conservation Biology, The University of California, Riverside, California 92521-0124 USA \\ ${ }^{2}$ Departamento de Conservación de Suelos y Aguas, Centro de Edafología y Biología Aplicada del Segura-CSIC, \\ Campus Universitario de Espinardo, P.O. Box 4195, 30100 Murcia, Spain \\ ${ }^{3}$ Chicago Botanic Garden, 1000 Lake Cook Road, Glencoe, Illinois 60022 USA \\ ${ }^{4}$ Weinberg College of Arts and Sciences, Northwestern University, Evanston, Illinois 60201 USA
}

\begin{abstract}
California coast live oak (Quercus agrifolia) forms tripartite symbiotic associations with arbuscular (AMF) and ectomycorrhizal (EMF) fungi. We selected oak individuals differing in topographic position and depth to groundwater (mesic valley vs. xeric hill sites) to investigate changes of tree mycorrhizal status in response to interannual rainfall variability. EMF root colonization, as well as hyphal abundance and viability in upper rhizosphere soil $(0-30 \mathrm{~cm})$, were negatively affected by severe multi-year drought, although not to the same extent in each topographic location. Oak trees growing in hill sites showed EMF colonization levels $<1 \%$ in upper roots during drought. By contrast, oaks in valley sites maintained much higher EMF colonization $(>19 \%)$ in upper roots during drought. EMF root colonization increased sharply at both topographic positions during the ensuing wet year (78\% in valley, $49 \%$ in hill), which indicates that the mycorrhizal status of roots in upper rhizosphere soil is highly responsive to interannual rainfall variability. Across sites and years, percentage EMF colonization and soil hyphal density and viability were strongly positively correlated with soil moisture potential, but percentage AMF root colonization was not. Interestingly, changes in percentage EMF root colonization and density of viable hyphae between a wet and a dry year were proportionally much greater in xeric hill sites than in mesic valley sites. The mycorrhizal status of oak trees was particularly responsive to changes in soil moisture at the hill sites, where roots in upper rhizosphere soil shifted from almost exclusively AMF during severe drought to predominantly EMF during the ensuing wet year. By contrast, the mycorrhizal status of oaks in the valley sites was less strongly coupled to current meteorological conditions, as roots in upper soil layers remained predominantly EMF during both a dry and a wet year. Canopy shading and hydraulic lift by oaks in valley sites likely contributed to maintain the integrity and viability of EMF roots and extraradical hyphae in upper rhizosphere soil during extended drought. Our results suggest that oak woodlands in water-limited ecosystems may become increasingly reliant on the AMF symbiosis under future climate change scenarios for the U.S. southwest and other world regions.
\end{abstract}

Key words: AMF; arbuscular mycorrhizal fungi; coast live oak; drought; ectomycorrhizal fungi; EMF; hydraulic lift; Quercus agrifolia; rhizosphere.

\section{INTRODUCTION}

The functioning of many plant species depends on the presence of mycorrhizae, a ubiquitous mutualism between certain soil fungi and the roots of plants (Smith and Read 1997, Allen et al. 2003). While the majority of plants usually form only one type of mycorrhizal association, the most common being with ecto- (EMF) or arbuscular mycorrhizal fungi (AMF), some plant species routinely form dual associations, i.e., with both types of mycorrhizae. Along with Alnus, Salix, Populus, or Eucalyptus, the genus Quercus forms mutualisms with both AMF and EMF (Smith and Read 1997). Seedlings

Manuscript received 12 October 2007; revised 2 June 2008; accepted 12 June 2008; final version received 11 July 2008. Corresponding Editor: B. B. Casper.

${ }^{5}$ E-mail: querejeta@cebas.csic.es of Quercus agrifolia Nee. (Fagaceae, California coast live oak) are generally colonized by AMF and EMF, sometimes within the same root segment, and later become predominantly EMF adult trees (EgertonWarburton and Allen 2001). The residual colonization by AMF often persists in mature coast live oak individuals, which suggests that the benefits that AMF and EMF symbionts confer to dually colonized host plants are only partially redundant, or might even be complementary.

Studies on plants colonized by both AMF and EMF have the potential to broaden our understanding of the similarities and differences of these two groups of fungi at larger scales (e.g., the geographical distribution of the two types of symbionts). Although both EMF and AMF can improve nutrient acquisition, especially phosphorus $(\mathrm{P})$ and nitrogen $(\mathrm{N})$, the benefits they provide to their 
host plants are not necessarily equivalent (Jones et al. 1998, Chen et al. 2000, Egerton-Warburton and Allen 2001, van der Heijden and Kuyper 2001, Dickie et al. 2002). For example, AMF and EMF differ in their enzymatic capabilities and, consequently, in their ability to exploit organic sources of nutrients, which may explain their dominance in different biomes. Many EMF have the potential to be directly involved in mobilization of $\mathrm{N}$ and $\mathrm{P}$ from the complex organic substrates in which they are largely sequestered in natural ecosystems (residues of plants and of soil microflora and fauna; Read and Pérez-Moreno 2003). By contrast, AMF are generally considered to lack the saprotrophic capability to enable $\mathrm{N}$ and $\mathrm{P}$ mineralization. Accordingly, the EMF symbiosis predominates in forest ecosystems with surface litter accumulation at intermediate latitudes and altitudes, whereas the AMF symbiosis dominates herbaceous and woody plant communities on mineral soils at lower latitudes (Read 1991).

AMF may be capable of enduring more negative soil water potentials than EMF (e.g., Jasper et al. 1989), as suggested by the fact that globally AMF is by far the most widespread mycorrhizal symbiosis in severely water-limited ecosystems (Allen et al. 1995). Soil moisture is a major driver of mycorrhizal colonization in drought-prone ecosystems (e.g., Swaty et al. 1998, 2004). Many studies have shown that the extent of EMF colonization of plant roots can be negatively affected by drought (Runion et al. 1997, Bell and Adams 2004, Izzo et al. 2005, Valdés et al. 2006, Kennedy and Peay 2007). Percentage AMF colonization may be adversely affected by severe soil drying (Jasper et al. 1989, He et al. 2002a, Lutgen et al. 2003, Apple et al. 2005), although some studies have reported little effect of drought on AMF root infection (Bryla and Duniway 1997, Titus et al. 2002). The carbon cost of the AMF symbiosis is almost certainly less than that of EMF (Jones et al. 1998, Leake et al. 2004, Gehring et al. 2006), so photosynthate limitation in severely water-stressed host plants that support both AMF and EMF could lead to preferential allocation to AMF in order to maximize the cost-benefit ratio of the carbon investment (Kummel and Salant 2006). Gehring et al. (2006) found that dually colonized cottonwoods (Populus angustifolia) growing at mesic riparian sites showed high EMF but low AMF colonization, whereas the proportion of AMF roots increased in comparatively drier sites located at higher elevation. They argued that the greater prevalence of AMF associations in cottonwoods growing in drier sites might be attributable to the lower carbon requirements of AMF than EMF.

Little is known, however, about how the mycorrhizal status of dually colonized plants in semiarid environments responds to extreme drought. To date, the few studies that have investigated changes in the relative prevalence of AMF vs. EMF with varying soil moisture in dually colonized plants have been conducted in wet riparian ecosystems (Lodge 1989, Lodge and Wentworth
1990, Gehring et al. 2006). Examining how the proportions of roots colonized by AMF and EMF shift with changing rainfall in $Q$. agrifolia should help elucidate whether mycorrhizal status in dually colonized plants is temporally stable or sensitive to changes in soil moisture in semiarid environments. It is particularly important to evaluate the responses of mycorrhizal roots within nutrient-rich topsoil layers, in which temporal and spatial changes in moisture content are most dramatic.

In a mesocosm study, Querejeta et al. (2003) found that $Q$. agrifolia seedlings tapping deep sources of water and conducting hydraulic lift (Caldwell et al. 1998) maintained the integrity and functionality of both EMF and AMF mycorrhizae in dry topsoil layers during severe drought. However the occurrence and potential implications of this process for adult tree mycorrhizal status have not yet been fully investigated in the field. In the present study, we examined interannual changes in tree mycorrhizal status in $Q$. agrifolia individuals growing at sites with contrasting topographic position and depth to the groundwater table. In Southern California, the exceptionally severe drought of 19992002 ended with the return of above-average precipitation in 2003, which provided a unique opportunity for studying the effects of extreme water stress and interannual rainfall variability on the mycorrhizal status of $Q$. agrifolia. We hypothesized that oak trees growing at mesic valley sites are buffered to some extent from interannual rainfall variability, and therefore maintain higher mycorrhizal root colonization levels in topsoil layers than oaks in xeric hill sites during drought. More specifically, we predicted that EMF root colonization as well as the abundance and viability of extraradical mycorrhizal hyphae in upper rhizosphere soil would be less adversely affected by drought in valley trees tapping deep sources of water than in hill trees.

\section{Materials And Methods}

\section{Study site}

The study was carried out in Lopez Canyon in the Western Riverside County Multi-species Reserve $\left(33^{\circ} 39^{\prime} 18^{\prime \prime} \mathrm{N}, 116^{\circ} 59^{\prime} 49^{\prime \prime} \mathrm{W}\right)$ in southern California, USA. The area has a Mediterranean-type semiarid climate and receives 298-mm precipitation annually (58-year mean), mostly between November and April. The soils are derived from decomposed granitic parent material and have a sandy loam texture (Lithic haploxerolls, Mollisols). The vegetation is dominated by exotic annual grasses introduced from the Mediterranean region, especially species of Bromus, with interspersed individuals and stands of coast live oak (Q. agrifolia Nee) and Engelmann oak (Q. engelmannii Greene). Agriculture and grazing in the area ended in the mid 1980s when the land was annexed to the Reserve to increase the habitat range for rare and endangered species.

We selected 10 coast live oak trees growing at sites with contrasting topographic position and access to 
TABLE 1. Site and host-tree parameters in valley and hill locations of the southern California (USA) oak community study area.

\begin{tabular}{lccc}
\hline \hline \multicolumn{1}{c}{$\begin{array}{c}\text { Site and tree } \\
\text { parameters }\end{array}$} & Valley & Hill & $P$ \\
\hline Elevation $(\mathrm{m})$ & 700 & 790 & n.a. \\
Soil depth $(\mathrm{cm})$ & $>200$ & $30-60$ & n.a. \\
Soil organic matter $(\%)$ & $2.87 \pm 0.33$ & $2.05 \pm 0.17$ & 0.016 \\
Soil total N (\%) & $0.129 \pm 0.008$ & $0.101 \pm 0.009$ & 0.011 \\
Soil total P (\%) & $0.023 \pm 0.005$ & $0.012 \pm 0.001$ & 0.022 \\
Tree diameter $(\mathrm{cm})$ & $75.9 \pm 11.8$ & $44.5 \pm 3.6$ & 0.021
\end{tabular}

Notes: Variation around mean values is \pm SE. Soil properties were analyzed in the $0-10 \mathrm{~cm}$ depth interval $(n=5$ trees $)$. All hill and valley sample pairs differ at $P<0.05$ by $t$ test; n.a. indicates that a $t$ test was not applicable.

groundwater. Five of the individuals selected for the study were located in mesic valley bottom sites where depth to the groundwater table is only 4-5 $\mathrm{m}$ (as measured in a nearby well). Another five trees were situated in north-facing xeric hill slopes, where depth to groundwater is presumably much greater. Valley and hill sites also differed in soil depth, soil fertility, organic matter content, and mean tree diameter (Table 1). At each topographic position, selected trees were located between 30 and $150 \mathrm{~m}$ apart from each other, and can thus be considered independent samples. Sampling was conducted in two years with widely contrasting rainfall (Fig. 1). The winter-spring of 2001-2002 was extraordinarily dry at the experimental area: only $28 \%$ of mean rainfall was recorded at the site, making it the driest November-May period on record. Further, 2002 was preceded by three consecutive dry years from 1999 to 2001 , in which $47 \%, 69 \%$, and $72 \%$ of mean annual precipitation, respectively, was recorded. By contrast, 2003 was a relatively wet year, with above-average precipitation during winter and spring (128\% of mean November-May rainfall).

\section{Soil and plant $\delta^{18} O$ and $\delta D$}

The naturally occurring concentration gradients in oxygen and hydrogen stable isotopes in the soil profile were used to investigate the occurrence of hydraulic lift within the rhizosphere of oak trees. During dry periods, the upper soil layers become enriched in the heavier isotopes (Deuterium [D] and ${ }^{18} \mathrm{O}$ ) due to evaporative fractionation, resulting in steep gradients in oxygen and hydrogen isotopic signatures with depth (Barnes and Turner 1998). However, trees conducting hydraulic redistribution typically show moister soil and less isotopically enriched soil water in their upper rhizosphere compared to surrounding areas (e.g., Dawson 1993, Querejeta et al. 2007). This is so because isotopically depleted groundwater or deep soil water not exposed to evaporation is exuded by roots into upper rhizosphere layers during this process. We predicted that soil water in oak rhizospheres would be less isotopically enriched in valley than in hill sites during drought, as conditions are much more conducive to hydraulic redistribution at the valley locations due to shallow groundwater.

In May 2002 (dry year) and May 2003 (wet year), soil profiles were sampled using a $9 \mathrm{~cm}$ diameter bucket auger at $15-\mathrm{cm}$ increments. Soil cores were taken from within the rhizosphere ( $<1 \mathrm{~m}$ from trunk base) of the selected oak trees (five located in mesic valley sites and another five located in xeric hill sites). Soil samples were immediately placed in sealed plastic bags upon collection. In addition, three stem samples per oak tree were collected in May 2002. The clipped stems were immediately placed in a capped vial, wrapped in Parafilm and stored in the freezer $\left(-20^{\circ} \mathrm{C}\right)$ until water was extracted for stable isotope analyses. Water was extracted from soil and stem samples using a cryogenic vacuum distillation line (Ehleringer and Osmond 1989). The water content of plant and soil samples was

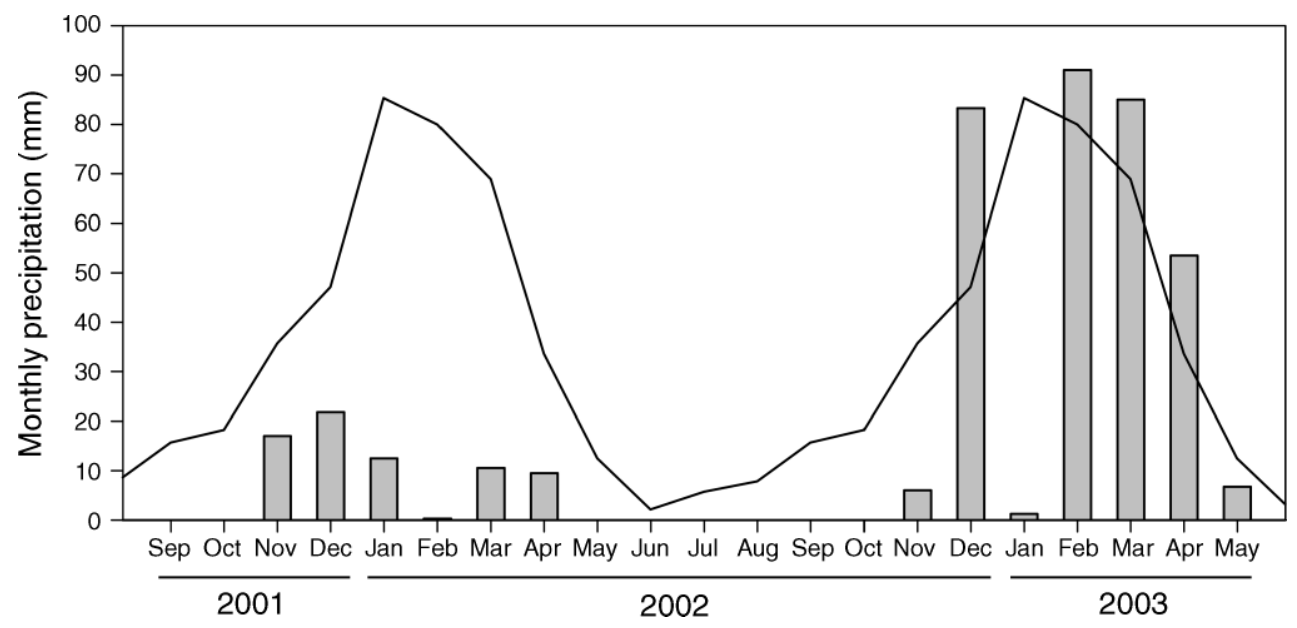

FIG. 1. Rainfall distribution during the 2001-2002 and 2002-2003 growing seasons at the Western Riverside County Multispecies Reserve in southern California, USA. Columns represent recorded monthly rainfall, while the line represents the 58-year mean monthly precipitation in the area. 
calculated according to differences in sample mass before and after thorough water extraction $\left(100^{\circ} \mathrm{C}, 3 \mathrm{~h}\right)$.

Oxygen and hydrogen stable isotope analyses were conducted at the Center for Stable Isotope Biogeochemistry of the University of California at Berkeley (Berkeley, California, USA). $\delta^{18} \mathrm{O}$ values were obtained by the $\mathrm{CO}_{2}: \mathrm{H}_{2} \mathrm{O}$ equilibration method: $500 \mu \mathrm{L}$ of the extracted water was injected into airtight vials flushed with 2000 or 3000 ppm $\mathrm{CO}_{2}$ in $\mathrm{He}$ (Tu et al. 2001). After $48 \mathrm{~h}, \mathrm{CO}_{2}$ in the head space was analyzed for its oxygen isotope ratio with a Finnigan MAT Delta Plus XL isotope mass spectrometer (IRMS; Thermo Scientific, Waltham, Massachusetts, USA) interfaced with a GasBench II and PAL-80 autosampler (Thermo Scientific). $\delta \mathrm{D}$ analyses were conducted using a chromium reactor on a Finnigan MAT H/Device dual inlet IRMS system (Thermo Scientific). All $\delta^{18} \mathrm{O}$ and $\delta \mathrm{D}$ values are expressed in delta notation (\%) relative to an accepted international standard (V-SMOW). Analytical precision was $\pm 0.18 \%$ for $\delta^{18} \mathrm{O}$ and $\pm 0.7 \%$ for $\delta \mathrm{D}$.

\section{Plant and soil water potentials}

Plant xylem water potential measurements were made on freshly clipped fine stems using a Scholander-type pressure bomb. Measurements were conducted before dawn (05:00-06:00 hours). Five adult oak trees were sampled at each topographic position during the May 2002 sampling campaign, as just described. Predawn xylem water potential measurements were conducted on three fine stems per target tree, immediately after clipping. Soil water potential was measured on subsamples of soil collected from the rhizosphere of target trees (five in mesic valley sites, and five in xeric hill sites) as described previously. Moisture potential measurements were conducted on soil samples on the same day in the laboratory using the chilled mirror dewpoint method (CX-2, Decagon Devices, Pullman, Washington, USA; Gee et al. 1992).

\section{Mycorrhizal abundance and community composition}

Root community.- Root samples were sieved from the soil cores, washed free of adhering soil, and fine roots $(\leq 1 \mathrm{~mm})$ were hand picked from each sample. A subsample of roots was stained using Trypan blue (Koske and Gemma 1989) and evaluated for percentage colonization by arbuscular mycorrhizal fungi (AMF) and ectomycorrhizal fungi (EMF) using the modified line-intersect method (McGonigle et al. 1990). The remaining EMF root tips were sorted into morphological types based on the color and texture of the mantle, the presence and type of emanating hyphae, and root branching pattern, and analyzed using molecular identification techniques.

Genomic DNA was extracted from replicated samples of each EMF morphotype, each comprising two to three root tips per sample. DNA extraction followed the methods described in Gardes and Bruns (1996), except that a glassmilk slurry was used for DNA binding and purification (GeneClean Spin Kit, Q-Biogene, Irvine, California, USA). Each sample of genomic DNA was used as a template for PCR using the primer pairs ITS1f/ITS4 (fungal nuclear ribosomal internal transcribed spacer, nrITS) or ITS1f/ ITS4b (Basidiomycetespecific nrITS). Positive controls using Agaricus bisporus and controls without DNA were included to check for reaction efficacy and contamination, respectively. Each PCR reaction contained $1 \mu \mathrm{L}$ of DNA template, $12 \mu \mathrm{L}$ Promega Master Mix, $1.5 \mu \mathrm{L}$ of each primer $(10 \mathrm{mmol} / \mathrm{L})$, and made up to $25 \mu \mathrm{L}$ with $\mathrm{dH}_{2} \mathrm{O}$. An initial denaturation and enzyme activation step of $3 \mathrm{~min}$ at $95^{\circ} \mathrm{C}$ was followed by amplification for 30 cycles at the following conditions: $30 \mathrm{~s}$ at $95^{\circ} \mathrm{C}, 30 \mathrm{~s}$ at $55^{\circ} \mathrm{C}, 60 \mathrm{~s}$ at $72^{\circ} \mathrm{C}$. A final 10 -min extension at $72^{\circ} \mathrm{C}$ completed the protocol. In most instances, DNA from EMF root tips amplified satisfactorily under these conditions and typically yielded $\sim 50 \mathrm{ng}$ amplicon $/ \mu \mathrm{L}$. For the small minority of tips that did not amplify with these conditions, we suspect that the material may have been senescent at the time of sampling and that the degraded DNA resulted in low amplicon yield. Amplicons were then used to generate RFLPs with the endonucleases AluI and HinfI. Preliminary RFLP analysis of amplicons using a variety of endonucleases demonstrated that AluI and HinfI provided the greatest number of diagnostic restriction fragment patterns and were subsequently used to cleave amplicons for RFLP analysis. Each reaction contained $1 \mu \mathrm{L}$ of PCR product, 5 units of restriction endonuclease, $1 \mu \mathrm{L}$ of the recommended buffer, and $0.1 \mu \mathrm{L}$ of bovine serum albumin (BSA), made up to $15 \mu \mathrm{L}$ with $\mathrm{dH}_{2} \mathrm{O}$. The restriction fragment sizes were determined with Kodak 1D software and imported into the T-Align program (Smith et al. 2005). Replicate RFLPs generated through separate PCRs from the same sample typically yielded the same major restriction fragments, thereby indicating the consistency of both PCR and RFLP reactions. Using the same ITS primer sets and endonucleases, we also compiled a site-specific database for EMF colonizing $Q$. agrifolia using sporocarps (Lindahl 2002) to provide a reference database for detection and identification of EMF in the root tip and hyphal samples. The database contained 234 species from 18 families and included both Basidiomycetes and Ascomycetes that are known to form EMF associations, epigeous and hypogeous taxa, and common non-mycorrhizal species, e.g., Coprinus, Melanoleuca, Pholiota, Collybia, Hypomyces, Agaricus, Lycoperdon, and a myxomycete. Restriction fragment patterns from each morphotype were compared against the reference database using T-Align, which allowed the unequivocal identification of all fragments within \pm 0.5 base pairs in all the profiles generated (data available online). ${ }^{6}$

Hyphal community.-Extramatrical hyphae were ex-

${ }^{6}\langle$ http://inismor.ucd.ie/ talign/index.html $\rangle$ 
tracted from $10 \mathrm{~g}$ duplicate subsamples of soil from each soil core using a modification of the procedure of Frey and Ellis (1997) followed by vital staining to determine the lengths of live fungal hyphae present in each location. For each subsample, $10 \mathrm{~g}$ of soil were suspended in $200 \mathrm{~mL}$ of sodium hexametaphosphate $(39.5 \mathrm{~g} / \mathrm{L})$ for $1 \mathrm{~h}$, washed through a $250-\mu \mathrm{m}$ mesh, resuspended in $300 \mathrm{~mL}$ of distilled water, left to settle for $15 \mathrm{~s}$, and then decanted through a $28-\mu \mathrm{m}$ mesh. Hyphae were rinsed out of the $28-\mu \mathrm{m}$ mesh and suspended in 12 $\mathrm{mL}$ of deionized water in a centrifuge tube and centrifuged for $10 \mathrm{~min}\left(19613 \mathrm{~m} / \mathrm{s}^{2}\right)$. The resulting pellet was rinsed in deionized water and centrifuged for $10 \mathrm{~min}$ (twice), after which, the supernatant was decanted and the hyphal pellet resuspended in $5 \mathrm{~mL}$ of fresh deionized water. This procedure typically yielded $20-25 \mathrm{mg}$ hyphae per soil sample.

Direct immunofluorescence with antibodies raised against spores of four of the major AMF genera was used to evaluate AMF viability, since the immune reaction will only proceed with live hyphae (Allen et al. 1999). For each subsample, $500 \mu \mathrm{L}$ aliquots of hyphal suspension were placed into each of five microfuge tubes followed by $100 \mu \mathrm{L}$ of an individual antiserum of the four major AMF genera (Scutellospora, Gigaspora, Acaulospora, Glomus) conjugated to FITC (fluorescein isothyocianate); $100 \mu \mathrm{L}$ of deionized water were added to the fifth tube as a control for fungal autofluorescence. Samples were incubated overnight at room temperature and then filtered and rinsed with deionized water over a membrane and mounted in glycerol. All samples were viewed under fluorescence microscopy (Zeiss Axioskop 2; Carl Zeiss MicroImaging, Thornwood, New York, USA) using an FITC filter combination (excitation 475$490 \mathrm{~nm}$, mirror $505 \mathrm{~nm}$, emission 503-535 nm) and scored for the presence or absence of FITC-labeled hyphae. Hyphal counts were taken in at least 100 fields of view per slide $(400 \times)$, and the length of hyphae was calculated and converted to meters of hyphae per gram of soil (Tennant 1975). Data were averaged over all four AMF genera for each sample.

The length of viable EMF hyphae was determined on subsamples incubated with fluoroscein diacetate (FDA). FDA is readily taken up by living cells and hydrolyzed to fluoroscein, which fluoresces green; nonviable samples do not fluoresce. An FDA stock solution was prepared by dissolving $5 \mathrm{mg}$ FDA in $1 \mathrm{~mL}$ acetone and adding $0.1 \mathrm{~mol} / \mathrm{L}$ phosphate buffer $(\mathrm{pH}$ 7.4) to give a final concentration of $50 \mu \mathrm{g} / \mathrm{L}$. A $500-\mu \mathrm{L}$ aliquot of the hyphal suspension was incubated with an equal amount of FDA stock solution for $5 \mathrm{~min}$ at room temperature and then immediately observed and scored in a Zeiss Axioskop 2 using fluorescence and a filter combination suitable for FITC. Fifty random fields of view per slide were scored for live hyphae using the gridline intersect method and converted to hyphal length per dry mass soil (Tennant 1975). Because the FDA test does not distinguish among the different groups of fungi present in an individual sample (mycorrhizal vs. saprotrophic fungi), we analyzed the hyphal pellets for their composition using molecular techniques and corrected the length of viable hyphae to reflect the abundance of only EMF in a sample.

DNA was extracted from each hyphal pellet using the same protocol used for the root tips (described earlier in this section), and PCR reactions undertaken using the same primer pairs. PCR products were amplified at least once to determine the reproducibility of the reaction. The amplified products were purified using a commercially available kit (QIAquick PCR Purification Kit; Qiagen, Valencia, California, USA) and cloned using the TOPO TA cloning system (Invitrogen Corporation, Carlsbad, California, USA) according to the manufacturer's instructions. Individual transformed colonies were selected and used directly in a PCR reaction with ITS1f/ITS4 and ITS1f/ITS4b primers as before. PCR products were then used in RFLP reactions until $\sim 10$ or more successful RFLP identifications were obtained using the RFLP matching procedure described for root tips. Because of the breadth of taxa in the fragmentmatching database, any sample patterns that did not provide a match with the database were considered to be non-EMF, which included both saprotrophic fungi and AMF. For each sample, we recorded the EMF species present as well as the incidence of EMF or non-EMF taxa, i.e., number of clones considered EMF or nonEMF. These latter counts were used to calculate the proportion of the hyphal pool comprising EMF as [(number of EMF clones)/(number of EMF + number of non-EMF clones)]. These values were then multiplied by the length of viable hyphae within the sample to provide a conservative estimate of viable EMF within the hyphal pool.

\section{Statistical analyses}

Statistical analyses were conducted using the SPSS 13.0 program (SPSS, Chicago, Illinois, USA). All percentage data were arcsine-square root transformed prior to analysis. Data were log transformed when required to ensure homoscedasticity. Plant and soil variables were analyzed by two way ANOVA with topographic position (hill vs. valley) and year (2002 vs. 2003) as main effects. Pearson's correlation coefficients among response variables were calculated as well.

\section{RESUlts}

\section{Soil water potential in oak rhizosphere}

Two-way ANOVA revealed that soil moisture potential within the upper rhizosphere $(0-30 \mathrm{~cm}$ depth) of oak trees was significantly affected $(P<0.001)$ by topographic position, year, and the interaction between these two factors. Interestingly, soil water potential in upper soil layers was far less negative (5.1-9.5 MPa difference) at the valley sites than at the hill sites during extreme drought (May 2002; Fig. 2). By contrast, soil water potential values were indistinguishable between valley 


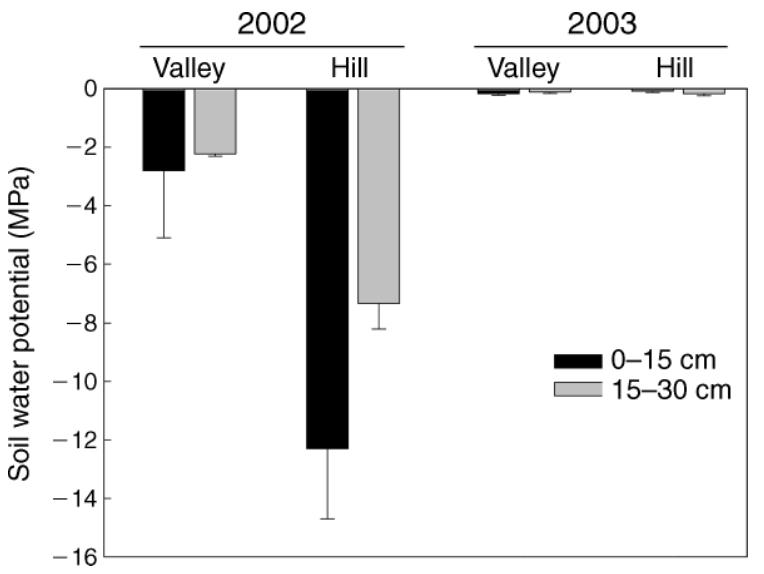

FIG. 2. Soil water potentials (mean and SE) at two levels in the upper rhizosphere soil $(0-30 \mathrm{~cm}$ depth) at valley and hill sites in May 2002 (dry year) and May 2003 (wet year). Values are reported in megapascals $(\mathrm{MPa})$.

and hill sites during the ensuing wet year (May 2003; Fig. 2). Therefore, the large inter-site difference observed during drought was not attributable to spatial variation in water input into topsoil layers during rainy periods.
Isotopic composition of soil water in oak rhizosphere

The hydrogen $(\delta \mathrm{D})$ and oxygen $\left(\delta^{18} \mathrm{O}\right)$ isotope composition of soil water in oak rhizosphere was significantly influenced by year $(P<0.001)$, but not by topographic position, although a significant topographic position $\times$ year interaction was detected for $\delta^{18} \mathrm{O}(P=$ 0.027). Both $\delta \mathrm{D}$ and $\delta^{18} \mathrm{O}$ were negatively correlated with soil moisture potential (Pearson's correlation coefficient $=-0.847, P<0.001$ and Pearson's correlation coefficient $=-0.905, P<0.001$, respectively) as a result of evaporative isotopic enrichment of remaining soil water during soil drying. The $\delta \mathrm{D}$ and $\delta^{18} \mathrm{O}$ values of soil water lay further to the right of the meteoric water line (MWL) at hill than valley sites during drought (May 2002), indicating more intense evaporative isotopic enrichment of soil water in the hill sites (Fig. 3). In sharp contrast to results obtained during drought, the isotopic composition of soil water fell nearer the MWL in hill than valley sites during the ensuing wetter period (May 2003). Given that winter/spring rainfall water lies on the MWL in Southern California, the May 2003 isotopic data suggest that moisture in the topsoil layers at the xeric hill sites came almost entirely from recent rain, whereas soil moisture at the valley sites comprised a mix of fresh rainfall water and residual soil water.

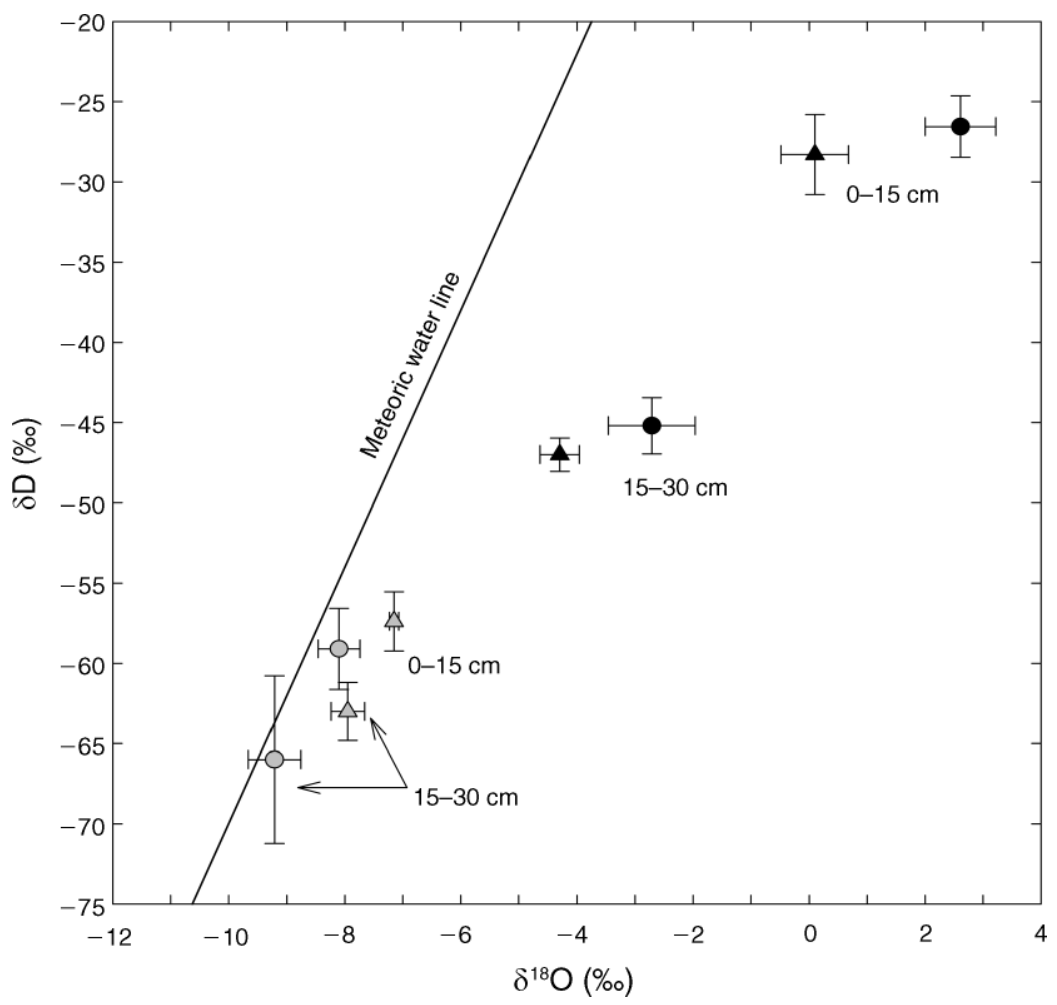

FIG. 3. Isotopic composition of soil water (mean $\pm \mathrm{SE}$ ) at two levels in the upper rhizosphere $(0-30 \mathrm{~cm}$ depth) of oak trees located at valley or hill sites. Values found in May 2002 (dry year) are shown as black triangles for valley sites and black circles for hill sites. Values encountered in May 2003 (wet year) are shown as gray triangles for valley sites and gray circles for hill sites. The local Meteoric Water Line (MWL) is effectively indistinguishable from the global MWL in southern California, USA (Williams and Rodoni 1997). 
TABLE 2. Ecto- and arbuscular-mycorrhizal hyphal length and root colonization in hill and valley Quercus agrifolia during extreme drought (May 2002) and during the ensuing year of above-average rainfall (May 2003).

\begin{tabular}{|c|c|c|c|c|c|c|c|}
\hline \multirow[b]{2}{*}{ Parameter and mycorrhizal type } & \multirow[b]{2}{*}{$\begin{array}{l}\text { Depth } \\
(\mathrm{cm})\end{array}$} & \multicolumn{3}{|c|}{ Dry (2002) } & \multicolumn{3}{|c|}{ Wet (2003) } \\
\hline & & Valley & Hill & $\begin{array}{c}P< \\
0.05 \dagger\end{array}$ & Valley & Hill & $\begin{array}{c}P< \\
0.05 \dagger\end{array}$ \\
\hline \multicolumn{8}{|c|}{ Hyphal length (m viable hyphae/g soil) } \\
\hline \multirow{2}{*}{ EMF } & $0-15$ & $9.55 \pm 2.46$ & $1.28 \pm 0.26$ & yes & $97.39 \pm 13.26$ & $48.53 \pm 5.45$ & yes \\
\hline & $15-30$ & $6.78 \pm 2.27$ & $1.07 \pm 0.25$ & yes & $119.50 \pm 15.57$ & $98.77 \pm 12.3$ & no \\
\hline \multirow[t]{2}{*}{ AMF } & $0-15$ & $11.42 \pm 2.07$ & $1.53 \pm 0.40$ & yes & $18.08 \pm 4.77$ & $12.85 \pm 1.83$ & no \\
\hline & $15-30$ & $7.19 \pm 1.66$ & $1.22 \pm 0.56$ & yes & $19.37 \pm 6.89$ & $20.33 \pm 4.55$ & no \\
\hline \multicolumn{8}{|l|}{ Root colonization ( $\%$ root length) } \\
\hline \multirow[t]{2}{*}{ EMF } & $0-15$ & $19.11 \pm 8.93$ & none detected & & $76.80 \pm 2.03$ & $55.66 \pm 12.5$ & no \\
\hline & $15-30$ & $19.14 \pm 8.04$ & $1.21 \pm 0.00$ & yes & $80.50 \pm 2.16$ & $41.59 \pm 15.8$ & yes \\
\hline \multirow[t]{2}{*}{ AMF } & $0-15$ & $6.08 \pm 1.85$ & $31.32 \pm 9.17$ & yes & $9.43 \pm 1.33$ & $45.56 \pm 7.79$ & yes \\
\hline & $15-30$ & $6.91 \pm 3.65$ & $22.07 \pm 1.41$ & yes & $7.05 \pm 0.77$ & $33.90 \pm 1.73$ & yes \\
\hline
\end{tabular}

Note: Mean values \pm standard error of the means are shown.

$\dagger$ Hill and valley sample pairs denoted "yes" differ significantly at $P<0.05$; cells with "no" do not differ significantly $(P>0.05)$ according to LSD post hoc tests.

\section{Oak water status during drought}

Predawn xylem water potential of oak trees in hill sites averaged $-3.5 \pm 0.3 \mathrm{MPa}(n=5)$ during drought, thus indicating severe plant water stress. By contrast, oak trees in valley sites showed significantly less negative $(P<0.001)$ predawn xylem water potentials $(-0.6 \pm 0.1$ $\mathrm{MPa} ; n=5)$ during drought, which strongly suggests root access to moist subsoil layers and/or groundwater. Mean stem-water content in oak trees was higher $(P<$ $0.001)$ in valley $(37.9 \pm 0.3 \% ; n=5$ trees $)$ than hill sites $(35.1 \pm 0.5 \% ; n=5$ trees) during drought, thus further indicating that valley trees were less water stressed. The stable isotope composition of oak stem water was very similar between hill and valley sites during drought (hill, $\delta \mathrm{D}=-55.7 \pm 0.5 \%$, $\delta^{18} \mathrm{O}=-6.7 \pm 0.1 \%$ o, $n=5$ trees; valley, $\delta \mathrm{D}=-56.2 \pm 1.1 \%$, $\delta^{18} \mathrm{O}=-6.7 \pm 0.2 \%$, $n=5$ trees). Stem water was far less enriched in $\mathrm{D}$ and ${ }^{18} \mathrm{O}$ than soil water in topsoil layers, thus indicating that oak trees in both hill and valley sites were drawing water from depths below $30 \mathrm{~cm}$ during drought.

\section{Mycorrhizal abundance and community composition}

Ectomycorrhizal fungi.-Percentage of ectomycorrhizal fungi (EMF) root colonization in upper rhizosphere soil was significantly $(P<0.001)$ affected by topographic position, year, and the interaction between these two factors. While fine-root density in topsoil layers was almost double in valley compared to hill sites during drought $(5.1 \pm 1.2 \mathrm{~m}$ vs. $2.6 \pm 0.5 \mathrm{~m}$ of fine-root length per soil core), differences in percentage EMF root colonization between topographic positions were at least one order of magnitude larger than that. Very few (15$30 \mathrm{~cm})$ or no $(0-15 \mathrm{~cm})$ EMF root tips were found in upper soil layers at hill sites during drought (Table 2). In contrast, oaks in valley sites maintained significant EMF root colonization $(>19 \%)$ in upper rhizosphere soil during drought. The percentage of roots colonized by EMF increased sharply at both topographic positions during the ensuing wet year (Table 2). Most important- ly, the change in percentage EMF root colonization between a dry and a wet year was proportionally much greater in hill sites (80-fold at $0-30 \mathrm{~cm}$ depth) than in valley sites (fourfold). EMF root colonization in upper rhizosphere soil was positively correlated with soil water potential (Pearson's correlation coefficient $=0.871, P<$ $0.001)$ and negatively correlated with soil water $\delta \mathrm{D}$ (Pearson's correlation coefficient $=-0.678, P<0.001$ ) and $\delta^{18} \mathrm{O}$ (Pearson's correlation coefficient $=-0.767, P$ $<0.001)$.

EMF hyphal abundance within the rhizosphere of oak trees was significantly affected by both topographic position $(P=0.026)$ and year $(P<0.001)$. The amount of EMF hyphae in upper rhizosphere soil remaining viable during extreme drought (Table 2) was sevenfold higher at mesic valley sites than at xeric hill sites $(P<$ $0.001)$. However, this difference decreased $(0-15 \mathrm{~cm})$ or disappeared $(15-30 \mathrm{~cm})$ during the ensuing wet year. At the time, hyphal abundance increased sharply, especially in hill sites, and percent viability of hyphae was $\sim 90 \%$ regardless of topographic position. EMF hyphal density was strongly positively correlated with soil moisture potential (Pearson's correlation coefficient $=0.879, P<$ $0.001)$ and negatively associated with soil water $\delta \mathrm{D}$ (Pearson's correlation coefficient $=-0.800, P<0.001$ ) and $\delta^{18} \mathrm{O}$ (Pearson's correlation coefficient $=-0.835, P$ $<0.001)$. The difference in viability-corrected soil EMF hyphal density between a dry and a wet year was much greater in hill sites (63-fold increase at 0-30 cm depth) than in valley sites (13-fold increase). This explains the highly significant $(P=0.006)$ topographic position $\times$ year interaction in the two-way ANOVA.

Based on unique RFLP banding patterns, we detected 46 different taxa of EMF on the roots of Q. agrifolia of which $89 \%$ were Basidiomycota and $11 \%$ Ascomycota. Of these, we identified 44 to species or genus by matching root-tip RFLP patterns with known sporocarp RFLP patterns. Ectomycorrhizal species richness and community composition differed significantly between 

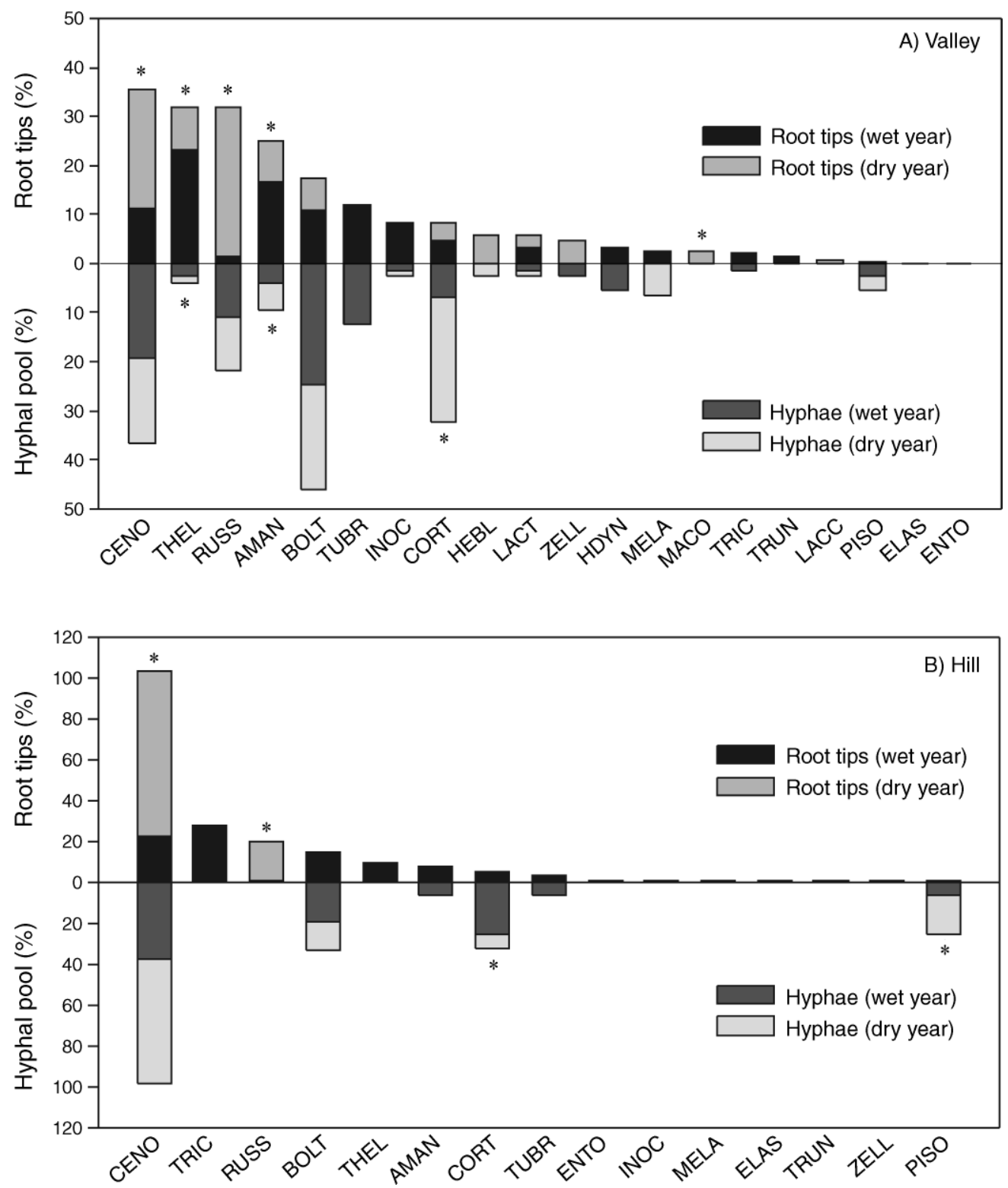

FIG. 4. Ectomycorrhizal community composition on the root tip and in the external hyphal pool in the valley and hill sites during an extreme drought (2002) and the subsequent wet year (2003). Note that columns representing EMF root tip or hyphal abundance values during the dry year are placed on top of columns representing values during the wet year. Abbreviations are: AMAN, Amanita; BOLT, Boletus; CENO, Cenococcum; CORT, Cortinarius; ELAS, Elasmomyces; ENTO, Entoloma; HEBL, Hebeloma; HYDN, Hydrotrya; INOC, Inocybe; LACC, Laccaria; LACT, Lactarius; MACO, Macowanites; MELA, Melanogaster; PISO, Pisolithus; RUSS, Russula; THEL, Thelephoraceae; TRIC, Tricholoma; TRUN, Truncocolumella; TUBR, Tuber; ZELL, Zelleromyces. Columns marked with an asterisk differ significantly $(P<0.05)$ in the percentage of root tips or hyphal pool clones between the drought year (2002) and subsequent wet year (2003); unmarked columns with both drought and wet year data do not differ significantly $(P>0.05)$.

hill and valley sites. Overall EMF species richness, as defined by the total number of EMF species within a topographic position, was significantly higher in valley than hill sites ( 43 vs. 29 species, respectively). When ranked by the cumulative abundance of each genus (drought + wet year), the EMF community was dominated by a few dominant genera with a relatively large number of subordinate taxa occurring at low frequencies $(<3 \%$ of the root tip community; Fig. 4). This was particularly evident in valley sites, where the rare taxa included hypogeous species (e.g., Macowanites), members of the Ascomycota (e.g., Hydnotrya), as well as species of Laccaria; these taxa were either absent or rarely recovered from the hill EMF community. Together with the significant differences in EMF root colonization between sites (Table 2), these findings 
support a strong influence of topographic position on EMF abundance, species richness, and community composition.

During drought, however, the valley and hill EMF communities were both dominated by Cenococcum geophilum in the root tips and hyphal pool (Fig. 4). In the hill sites, C. geophilum accounted for $81 \%$ of the roots tips, with the remainder colonized by Russula brevipes (Fig. 4B). With the advent of above-average rainfall (2003), Russula all but disappeared from root tips. In fact, Russula declined in abundance from $18.5 \%$ to $1.5 \%$ of root tips in the hill sites, and the community comprised at least 10 taxa that had not been observed during the preceding drought, including Tricholoma, Thelephoraceae, Amanita, Cortinarius, and Tuber. Similarly, significant shifts in EMF community composition also marked the transition from prolonged drought to above-average rainfall in the valley sites (Fig. 4A). A high portion of roots were colonized by $C$. geophilum (24.5\% of root tips) along with Russula (seven species, $30.4 \%$ ), Amanita (two species, 8.5\%), Thelephoraceae $(8.6 \%)$, and Boletus (two species, $6.4 \%$ ) during drought conditions. In addition, species of Hebeloma and two sequestrate Russulaceae, Zelleromyces and Macowanites, were only recovered from root tips during drought. With above-average rainfall, the proportion of root tips colonized by C. geophilum and Russula declined significantly. In fact, Russula declined in prevalence from $30.4 \%$ to $1.3 \%$ of root tips in the valley sites. Instead, during the wet year the EMF community became dominated by the Thelephoraceae (23.2\%), Amanita (3 species, 16.6\%), Tuber (11.9\%), and Inocybe ( 2 species, $8.5 \%$ ), and at least 15 taxa that were absent or poorly represented during the preceding drought (e.g., Hydnotrya, Tricholoma). However, the abundance of Cortinarius, Boletus, and Lactarius on root tips did not differ significantly between drought and wet periods in valley sites $(P>0.05)$.

EMF species that were abundant in root tips were not necessarily those that dominated the hyphal pool (Fig. 4). For example, Inocybe and the Thelephoraceae were more frequent in root tips than in the external mycelial pool, whereas Pisolithus, Boletus, and Cortinarius were abundant in the hyphal pool, but not the root tips. These patterns were present in both valley and hill sites, and were consistent with the exploration strategies proposed for each genus by Agerer (2001). In general agreement with the root-tip community, we found that the hyphal pool in valley sites was taxonomically richer than that of the hill sites ( 15 vs. six genera, respectively), and that the majority of the EMF hyphal pool comprised Cenococcum geophilum during drought in both sites. Only four EMF genera were found in the hyphal pool of the hill sites during drought (Fig. 4B), and only two additional taxa were recovered from the hyphal pool during the subsequent wet year (Amanita, Tuber). The valley hyphal pool (Fig. 4A) was characterized by taxa that showed three patterns of response:

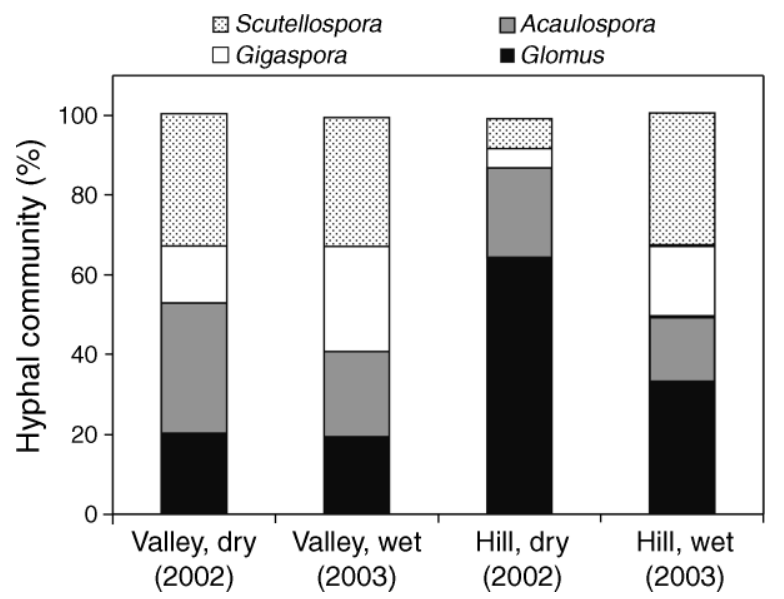

FIG. 5. Arbuscular mycorrhizal community composition in hill and valley sites during a drought year (2002) and subsequent wet year (2003).

(1) greater relative abundance during drought (e.g., Hebeloma, Melanogaster, Cortinarius), (2) greater relative abundance during the wet year (e.g., Tuber, Tricholoma, Thelephoraceae, Zelleromyces), or (3) no significant difference in relative abundance between years (e.g., Boletus, Amanita, Lactarius, Russula, Pisolithus).

Arbuscular mycorrhizal fungi.-The percentage of fine-root length colonized by AMF was significantly affected by topographic position $(P=0.001)$, but not by year $(P=0.055)$. In fact, arbuscular mycorrhizal fungi (AMF) root colonization was always significantly higher in hill than valley trees and increased only moderately during the wet year, especially in oaks at hill sites. AMF colonization rate in oak trees was not significantly correlated with soil water potential (Pearson's correlation coefficient $=-0.084, P=0.612$ ), soil water isotopic composition $(\delta \mathrm{D}$, Pearson's correlation coefficient $=$ $-0.195, P=0.234 ; \delta^{18} \mathrm{O}$, Pearson's correlation coefficient $=-0.167, P=0.309)$, or percentage EMF colonization of roots (Pearson's correlation coefficient $=-0.106, P=$ 0.520). The abundance of viable AMF hyphae followed the same pattern as EMF hyphae, i.e., a higher AMF yield in valley oaks during drought and no significant difference between topographic locations during the ensuing wet year (Table 2).

Using immunofluorescence, we detected four genera of AMF in the external hyphal pool in both hill and valley locations (Fig. 5). The AMF community in the valley sites comprised mostly Gigasporaceae (Gigaspora, Scutellospora), whereas Glomus dominated the hyphal pool in hill sites. The valley AMF community varied little between drought and wet years; we only detected a significant $(P<0.05)$ increase in the relative abundance of Gigaspora in the hyphal pool between drought and the following wet year (drought, $14.2 \% \pm 5 \%$ of hyphal length; wet, $26.4 \% \pm 7 \%$ ). By contrast, the AMF hyphal 
community in the hill sites underwent significant shifts in composition between drought and wet years. During drought, Glomus clearly dominated the hyphal pool $(64.3 \% \pm 2 \%)$, while the wet year was marked by a significant increases in the abundance of the Gigasporaceae $(33.0 \% \pm 4 \%$ Scutellospora, $17.8 \% \pm 0.1 \%$ Gigaspora) with concomitant decreases in the prevalence of Glomus $(33.2 \% \pm 8 \%)$.

\section{DisCUSSION}

The data presented here clearly show that interannual rainfall variability and soil moisture are major environmental factors influencing the mycorrhizal status of coast live oaks in mediterranean-type ecosystems of Southern California. The observed decline in mycorrhizal root colonization and hyphal abundance in topsoil layers during drought is in agreement with previous studies reporting similar if less dramatic results (Hunt and Fogel 1983, Titus et al. 2002, Lutgen et al. 2003, Bell and Adams 2004, Izzo et al. 2005, Kennedy and Peay 2007, Querejeta et al. 2007). We found some temporally consistent differences in tree mycorrhizal status between contrasting topographic positions, such as higher EMF root colonization levels in valley than hill sites in two consecutive years. However, it is important to emphasize that these temporally consistent differences are not per se the focus of this paper: various factors that covary with topography (such as soil fertility and organic matter content) have been individually shown to affect plant mycorrhizal status in previous studies (Gehring and Whitham 1994, 1995, Gehring et al. 1998, Swaty et al. 1998, 2004). The most interesting and intriguing finding of this study was that interannual changes in tree mycorrhizal status and hyphal abundance in upper rhizosphere soil were comparatively much more dramatic for oaks in xeric hill sites than for those in mesic valley sites.

Oaks in hill sites were severely water stressed and showed negligible EMF root colonization in upper rhizosphere soil during the extreme drought of 2002. However, hill oaks showed low but significant EMF root colonization in the $30-60 \mathrm{~cm}$ depth interval $(6 \% \pm$ $4.3 \%, n=5$ trees; J. I. Querejeta, L. M. EgertonWarburton, and M. F. Allen, unpublished data), where soil water potential was less negative than in upper layers $(-5.4 \pm 1.9 \mathrm{MPa} ; n=5$ trees $)$. Since droughtcaused photosynthate limitation to EMF colonization would be expected to exert uniformly negative effects across depths, our data indicate that exceedingly low moisture potential in upper rhizosphere soil was itself an important factor hampering EMF root colonization in xeric hill sites. The majority of EMF taxa in coast live oak woodlands may be unable to endure soil water potentials as low as $-12 /-7 \mathrm{MPa}$, regardless of carbon supply rate from the host plant (Coleman et al. 1989). Similarly, Bell and Adams (2004) found that EMF colonization in pines was negligible in dry topsoil layers but increased significantly in deeper, moister layers during summer drought.

Unlike EMF, the percentage of root length colonized by $\mathrm{AMF}$ in upper rhizosphere soil at hill sites remained $\sim 20-30 \%$ during severe drought. Percentage AMF root colonization was the only mycorrhizal parameter that was not correlated with soil water potential in our study. The prospect that AMF could be capable of absorbing and translocating resources to their host plants when soil water potential is as low as $-12 \mathrm{MPa}$ is intriguing. Desert shrubs have been shown to maintain significant levels of AMF root colonization in extremely dry soil (e.g., He et al. 2002a,b). AMF might be more efficient than EMF at scavenging for nutrients in dry soil, as suggested by their dominance in arid and semiarid ecosystems globally (Allen et al. 1995). Alternatively, AMF might be unable to take up significant amounts of nutrients from very dry soil, possibly becoming temporarily parasitic on their host plant (Denison et al. 2003). That Glomus, an AMF genus that has shown potential for parasitic associations, dominated the xeric hill sites during drought supports this possibility (Klironomos 2003). Glomus dominance of AMF soil communities in xeric sites was also reported by Egerton-Warburton et al. (2007) in a cross-site study of five grasslands across the United States.

EMF root-colonization levels in topsoil layers increased drastically at hill sites as soon as moisture became non-limiting during a wet year. As noted above, we observed that some EMF roots persisted in deeper, less dry soil layers throughout drought, which presumably favored colonization of roots in the upper rhizosphere after the onset of more favorable moisture conditions. Bornyasz et al. (2005) showed that $Q$. agrifolia roots can grow very deep into the soil/bedrock profile (at least $4 \mathrm{~m}$ ) and that these deep roots are often extensively colonized by EMF. Our data suggest that deeper soil layers provide refugia for EMF during dry years, which may buffer the amount of change the whole tree experiences in its mycorrhizal community between wet and dry years.

Low soil hyphal density and viability at hill sites in May 2002 indicate that the development and functioning of extraradical mycorrhizal mycelium in topsoil layers was severely hampered by extremely negative soil water potentials (and possibly by limited photosynthate supply) during severe drought. Mycelial growth of most EMF taxa is strongly inhibited even by relatively mild moisture stress (-1/-3 MPa; Coleman et al. 1989). The dramatic proliferation of viable hyphae observed at hill sites during the ensuing wet year demonstrates that soil moisture is the major driver of hyphal productivity in this dual EMF/AMF system. In particular, greatly enhanced EMF root colonization can explain the sharp increase in hyphal abundance observed during the wet year at hill sites, as EMF generally produce much more abundant extraradical mycelia than AMF (Leake et al. 2004). 
The mycorrhizal status of oak trees in xeric hill sites displayed remarkable responsiveness to changing soil moisture conditions. Within only twelve months, oak roots in upper rhizosphere soil shifted from almost exclusively AMF during severe drought to predominantly EMF during the ensuing wet year. This flexibility in mycorrhizae formation could partly explain the success of coast live oaks in diverse sites (e.g., xeric uplands and mesic lowlands). Watson et al. (1990) reported that AMF root colonization in oaks of the subgenus Erythrobalanus increased when soils were either very dry or very wet, whereas the more typical EMF were favored by moderate soil moisture. The ability to modulate the relative dominance of these two mycorrhizal associations in nutrient-rich topsoil layers may be a highly adaptive strategy for plants growing in mediterranean-type semiarid environments, where rainfall is erratic and unpredictable. The benefits that AMF and EMF provide to their host plants are not equivalent and might be strongly determined by both prevailing environmental conditions and host ecophysiological status (Gehring et al. 2006, Kummel and Salant 2006). Egerton-Warburton and Allen (2001) showed that intraannual fluctuation in soil moisture can also affect the mycorrhizal status of $Q$. agrifolia, although to a lesser extent than interannual fluctuations involving cumulative effects of multi-year drought and greater extremes of water availability.

In sharp contrast to trees at xeric hill sites, oaks in mesic valley sites had access to deep moisture during extended drought, as indicated by their moderate waterstress level. Valley oaks supported considerable EMF root colonization in upper soil layers during drought, even after four consecutive years of below-average precipitation (1999-2002). Interestingly, moisture potential in upper rhizosphere soil was 5-9 MPa higher at valley than hill sites during drought, which undoubtedly favored the persistence of EMF roots and hyphae. Coleman et al. (1989) demonstrated that the mycelia of some drought-adapted EMF can maintain growth at water potentials as low as $-3 \mathrm{MPa}$ when grown in pure culture. Therefore, the moderately negative water potentials found in the topsoil of the valley sites during drought (between -2 and $-3 \mathrm{MPa}$ ) should have allowed at least some EMF roots and extraradical hyphae to remain functional.

Shading of the ground surface by a continuous tree canopy likely reduced evaporative moisture loss in the mesic valley sites (Parker and Muller 1982). Most importantly, the data strongly suggest that water efflux from shallow roots (hydraulic lift) contributed to prevent excessive desiccation of topsoil layers in the valley sites (Querejeta et al. 2007). Trees conducting hydraulic lift typically exhibit slow and moderate declines in rhizosphere soil moisture potential during prolonged dry spells (Caldwell et al. 1998, MillikinIshikawa and Bledsoe 2000, Espeleta et al. 2004, KurzBesson et al. 2006), which is what was found in valley oaks. Less isotopically enriched topsoil water at valley than hill sites during drought was thoroughly consistent with root efflux of water lifted from deep moisture sources which were not exposed to evaporation (i.e., wet subsoil or groundwater). Direct water transfer from well-hydrated oaks to intimately associated mycorrhizal fungi likely contributed to maintain significant EMF root colonization and high viability of rhizosphere hyphae during severe drought in valley sites (Querejeta et al. 2003, 2007). Oaks in valley sites and their associated EMF fungi may have been able to continue exploiting the nutrient-rich topsoil layers during extended drought, as it has been suggested that water efflux from shallow roots (hydraulic lift) and water exudation by active EMF hyphal tips could help mobilize nutrients in dry soil (Caldwell et al. 1998, Sun et al. 1999, EgertonWarburton et al. 2008).

In contrast to mesic valley sites, we found no evidence whatsoever of hydraulic lift in xeric hill sites during drought. The severe water stress exhibited by hill oaks during the dry year indicates that they had little if any access to deep moisture or groundwater, so they were unable to prevent extreme desiccation of upper rhizosphere soil layers through hydraulic redistribution. In addition, topsoil moisture potential in hill sites $(-12 /-7$ $\mathrm{MPa}$ ) was well below the lower threshold for hydraulic lift occurrence in California oaks (-4.5 MPa, Ishikawa and Bledsoe 2000; -4.2 MPa, Querejeta et al. 2003). Further, trees in hill sites were isolated and did not form a continuous canopy, so canopy shading of the ground was less effective to prevent topsoil moisture evaporation than in valley sites. Tree-size-related differences in rooting volume and depth, plant internal water capacitance (Phillips et al. 2003), or plant carbon storage may have also played a role in the disparate mycorrhizal responses to drought of valley and hill oaks, as the latter trees were significantly smaller.

The EMF communities in oak rhizospheres were comprised of a few dominant species with a higher number of rare EMF species, a similar result to that reported by other authors (e.g., Peter et al. 2001, Erland and Taylor 2002, Taylor 2002). Ectomycorrhizal fungi belonging to the Ascomycota (including Cenococcum, Thelephoraceae, Tuber) were well represented in the EMF community in both hill and valley sites, which agrees well with the results obtained by Smith et al. (2007) in a xeric Quercus woodland in California. Members of the Ascomycota have been shown to dominate EMF communities in stressful sites and under stressful conditions (e.g., Gehring et al. 1998). In particular, we found that Cenococcum clearly dominated the EMF community in the xeric hill locations during the dry year, both on root tips and in the soil hyphal pool. Other studies have reported that the prevalence of Cenococcum in EMF communities increased during dry periods (Pigott 1982, Jany et al. 2003, Bueé et al. 2005), as this species (or species complex; see Smith et al. 2007) 
is well adapted to endure very low soil water potentials (Coleman et al. 1989).

The results of this study suggest that oaks in waterlimited ecosystems might become increasingly dependent on the AMF symbiosis for satisfying their nutritional requirements under projected climate change scenarios. Regional climate models predict warmer conditions and less and more irregular rainfall for many oak woodland ecosystems around the world (e.g., those in the U.S. southwest, parts of Mexico, the Mediterranean Basin, and other similar areas; IPCC 2007). Whereas EMFdominated systems have a conservative nutrient cycle in which trees access organic $\mathrm{N}$ via ectomycorrhizal fungi (thus bypassing mineralization processes by free-living microbes), AMF systems rely heavily on $\mathrm{N}$ mineralization (Millard et al. 2007). Hence, any decrease in EMF dominance caused by increasing aridity would be expected to have important consequences for litter decomposition, nutrient cycling, and tree nutrition in dryland oak woodlands. Mobilization and transfer of nutrients from the organic litter layer by EMF might be inhibited if drought becomes more frequent and/or severe, thus leading to increased host-plant reliance on inorganic forms of $\mathrm{N}$ and $\mathrm{P}$ which are more readily accessible to AMF. A climate-change-induced decrease in dominance by EMF in favor of AMF would also be expected to affect rhizosphere carbon flow in oak woodlands because the carbon cost of the EMF symbiosis is higher than that of the AMF symbiosis (Leake et al. 2004). Competitive interactions between oaks and the grass understory, and oak seedling regeneration success might also be affected by decreased prevalence of EMF in ways that are difficult to predict (Dickie et al. 2002).

In summary, we found that EMF root colonization in $Q$. agrifolia is very responsive to interannual rainfall variability, particularly at xeric sites, but also appears to be remarkably resilient to severe, multi-year drought. The ability to shift the relative dominance of the EMF and AMF symbioses in upper roots depending on soil moisture availability could be a highly adaptive trait in drought-prone ecosystems. Interestingly, the mycorrhizal status of oak trees in valley sites was less strongly coupled to current meteorological conditions than that of trees in hill sites, as upper roots in the former remained predominantly EMF during both dry and wet periods. Taproot access to deep moisture, hydraulic lift, and canopy shading appeared to attenuate the adverse effects of severe drought on EMF in valley sites. We hypothesize that host plants tapping deep moisture sources during extended drought might be able to support crucial biogeochemical processes in nutrientrich topsoil through effects on mycorrhizae, as these symbionts play key roles in belowground carbon flux and turnover, mycorrhizosphere microbial activity, organic matter decomposition, and nutrient cycling. Manipulative field experiments involving irrigation and/or rain exclusion within the rhizosphere of dually colonized trees with differential access to groundwater should prove useful for explicitly testing the mycorrhizal dynamics predicted by this study.

\section{ACKNOWLEDGMENTS}

J. I. Querejeta and L. M. Egerton-Warburton contributed equally to this work. This work was supported by the National Science Foundation Biocomplexity Program (DEB 9981548) and a Fulbright postdoctoral fellowship awarded to J. I. Querejeta by the Spanish Ministerio de Educación y Ciencia (MEC). J. I. Querejeta also acknowledges support from the "Ramón y Cajal" Program of MEC. The authors are grateful to Amy Lindahl, Roberto Lepe, and Angela López for their help with field and laboratory work. We also thank the reviewers for many improvements to the manuscript.

\section{Literature Cited}

Agerer, R. 2001. Exploration types of ectomycorrhizae-a proposal to classify ectomycorrhizal mycelial systems according to their patterns of differentiation and putative ecological importance. Mycorrhiza 11:107-114.

Allen, E. B., M. F. Allen, D. Helm, J. M. Trappe, R. Molina, and E. Rincon. 1995. Patterns and regulation of mycorrhizal plant and fungal diversity. Plant and Soil 170:47-62.

Allen, M. F., L. M. Egerton-Warburton, E. B. Allen, and O. Karen. 1999. Mycorrhizae in Adenostoma fasciculatum Hook. \& Arn.: a combination of unusual ecto- and endo-forms. Mycorrhiza 8:225-228.

Allen, M. F., W. Swenson, J. I. Querejeta, L. M. EgertonWarburton, and K. K. Treseder. 2003. Ecology of mycorrhizae: a conceptual framework for complex interactions among plants and fungi. Annual Review of Phytopathology 41:271-303.

Apple, M. E., C. I. Thee, V. L. Smith-Longozo, C. R. Cogar, C. E. Wells, and R. S. Nowak. 2005. Arbuscular mycorrhizal colonization of Larrea tridentata and Ambrosia dumosa roots varies with precipitation and season in the Mojave Desert. Symbiosis 39:131-135.

Barnes, C. J., and J. V. Turner. 1998. Isotopic exchange in soil water. Pages 137-162 in C. Kendall and J. J. McDonnell, editors. Isotope tracers in catchment hydrology. Elsevier, Amsterdam, The Netherlands.

Bell, T. L., and M. A. Adams. 2004. Ecophysiology of ectomycorrhizal fungi associated with Pinus spp. in low rainfall areas of Western Australia. Plant Ecology 171:35-52.

Bornyasz, M. A., R. C. Graham, and M. F. Allen. 2005. Ectomycorrhizae in a soil-weathered granitic bedrock regolith: linking matrix resources to plants. Geoderma 126:141160.

Bryla, D. R., and J. M. Duniway. 1997. Growth, phosphorus uptake, and water relations of safflower and wheat infected with an arbuscular mycorrhizal fungus. New Phytologist 136: 581-590.

Buée, M., D. Vairelles, and J. Garbaye. 2005. Year-round monitoring of diversity and potential metabolic activity of the ectomycorrhizal community in a beech (Fagus silvatica) forest subjected to two thinning regimes. Mycorrhiza 15:235245.

Caldwell, M. M., T. E. Dawson, and J. H. Richards. 1998. Hydraulic lift: consequences of water efflux from the roots of plants. Oecologia 113:151-161.

Chen, Y. L., M. C. Brundrett, and B. Dell. 2000. Effects of ectomycorrhizas and vesicular-arbuscular mycorrhizas, alone and in competition, on root colonization and growth of Eucalyptus globulus and E. urophylla. New Phytologist 146:545-556.

Coleman, M. D., C. S. Bledsoe, and W. Lopushinsky. 1989. Pure culture response of ectomycorrhizal fungi to imposed water stress. Canadian Journal of Botany 67:29-39. 
Dawson, T. E. 1993. Hydraulic lift and water use by plants: implications for water-balance, performance and plant-plant interactions. Oecologia 95:565-574.

Denison, R. F., C. Bledsoe, M. Kahn, F. O'Gara, E. L. Simms, and L. S. Thomashow. 2003. Cooperation in the rhizosphere and the "free rider" problem. Ecology 84:838-845.

Dickie, I. A., R. T. Koide, and K. C. Steiner. 2002. Influences of established trees on mycorrhizas, nutrition, and growth of Quercus rubra seedlings. Ecological Monographs 72:505-521.

Egerton-Warburton, L. M., and M. F. Allen. 2001. Endo- and ectomycorrhizas in Quercus agrifolia Nee. (Fagaceae): patterns of root colonization and effects on seedling growth. Mycorrhiza 11:283-290.

Egerton-Warburton, L. M., N. C. Johnson, and E. B. Allen. 2007. Mycorrhizal community dynamics following nitrogen fertilization: a cross-site test in five grasslands. Ecological Monographs 77:527-544.

Egerton-Warburton, L. M., J. I. Querejeta, and M. F. Allen. 2008. Efflux of hydraulically lifted water from mycorrhizal fungal hyphae during imposed drought. Plant Signaling and Behavior 3:68-71.

Ehleringer, J. R., and C. B. Osmond. 1989. Stable isotopes. Pages 281-300 in R. W. Pearcy, J. R. Ehleringer, H. A. Mooney, and P. W. Rundel, Plant physiological ecology: field methods and instrumentation. Chapman and Hall, New York, New York, USA.

Erland, S., and A. F. S. Taylor. 2002. Diversity of ectomycorrhizal communities in relation to the abiotic environment. Pages 163-200 in M. van der Heijden and I. Sanders, editors. The ecology of mycorrhizas. Ecological studies series. Volume 157. Springer-Verlag, Berlin, Germany.

Espeleta, J. F., J. B. West, and L. A. Donovan. 2004. Speciesspecific patterns of hydraulic lift in co-occurring adult trees and grasses in a sandhill community. Oecologia 138:341-349.

Frey, J. E., and J. R. Ellis. 1997. Relationship of soil properties and soil amendments to response of Glomus intraradices and soybeans. Canadian Journal of Botany 75:483-491.

Gardes, M., and T. D. Bruns. 1996. Community structure of ectomycorrhizal fungi in a Pinus muricata forest: above- and below-ground views. Canadian Journal of Botany 74:15721583.

Gee, G. W., M. D. Campbell, G. S. Campbell, and J. H. Campbell. 1992. Rapid measurement of low soil water potentials using a water activity meter. Soil Science Society of America Journal 56:1068-1070.

Gehring, C. A., R. C. Mueller, and T. G. Whitham. 2006. Environmental and genetic effects on the formation of ectomycorrhizal and arbuscular mycorrhizal associations in cottonwoods. Oecologia 149:158-164.

Gehring, C. A., T. C. Theimer, T. G. Witham, and P. Keim. 1998. Ectomycorrhizal fungal community structure of pinyon pines growing in two environmental extremes. Ecology 79 : 1562-1572.

Gehring, C. A., and T. G. Whitham. 1994. Comparisons of ectomycorrhizae across extremes of soil type and herbivory. American Journal of Botany 81:1509-1516.

Gehring, C. A., and T. G. Whitham. 1995. Duration of herbivore removal and environmental stress affect the ectomycorrhiza of pinyon pines. Ecology 76:2118-2123.

He, X. L., S. Mouratov, and Y. Steinberger. 2002a. Temporal and spatial dynamics of vesicular-arbuscular mycorrhizal fungi under the canopy of Zygophyllum dumosum Boiss. in the Negev Desert. Journal of Arid Environments 52:379-387.

He, X. L., S. Mouratov, and Y. Steinberger. 2002b. Spatial distribution and colonization of arbuscular mycorrhizal fungi under the canopies of desert halophytes. Arid Land Research and Management 16:149-160.

Hunt, G. A., and R. Fogel. 1983. Fungal hyphal dynamics in a Western Oregon Douglas-fir stand. Soil Biology and Biochemistry 15:641-649.
IPCC. 2007. Fourth assessment report of the intergovernmental panel on climate change. Cambridge University Press, Cambridge, UK.

Izzo, A., J. Agbowo, and T. D. Bruns. 2005. Detection of plotlevel changes in ectomycorrhizal communities across years in an old-growth mixed-conifer forest. New Phytologist 166: 619-630.

Jany, J. L., F. Martin, and J. Garbaye. 2003. Respiration activity of ectomycorrhizas from Cenococcum geophilum and Lactarius sp. in relation to soil water potential in five beech forests. Plant and Soil 255:487-494.

Jasper, D. A., L. K. Abbott, and A. D. Robson. 1989. Hyphae of a vesicular-arbuscular mycorrhizal fungus maintain infectivity in dry soil except when the soil is disturbed. New Phytologist 112:101-107.

Jones, M. D., D. M. Durall, and P. B. Tinker. 1998. A comparison of arbuscular and ectomycorrhizal Eucalyptus coccifera: growth response, phosphorus uptake efficiency and external hyphal production. New Phytologist 140:125-134.

Kennedy, P. G., and K. G. Peay. 2007. Different soil moisture conditions change the outcome of the ectomycorrhizal symbiosis between Rhizopogon species and Pinus muricata. Plant and Soil 291:155-165.

Klironomos, J. N. 2003. Variation in plant response to native and exotic arbuscular mycorrhizal fungi. Ecology 84:22922301.

Koske, R. E., and J. N. Gemma. 1989. A modified procedure for staining roots to detect VA-mycorrhizas. Mycological Research 92:486-505.

Kummel, M., and S. W. Salant. 2006. The economics of mutualism: optimal utilization of mycorrhizal mutualistic partners by plants. Ecology 87:892-902.

Kurz-Besson, C., D. Otieno, R. L. do Vale, R. Siegwolf, M. Schmidt, A. Herd, C. Nogueira, T. S. David, J. S. David, J. Tenhunen, J. S. Pereira, and M. Chaves. 2006. Hydraulic lift in cork oak trees in a savanna-type Mediterranean ecosystem and its contribution to the local water balance. Plant and Soil 282:361-378.

Leake, J., D. Johnson, D. Donnelly, G. Muckle, L. Boddy, and D. Read. 2004. Networks of power and influence: the role of mycorrhizal mycelium in controlling plant communities and agroecosystem functioning. Canadian Journal of Botany 82: 1016-1045.

Lindahl, A. 2002. Ecto- and arbuscular mycorrhizal fungi in transplanted oak seedlings in a southern California Oak (Quercus agrifolia: Fagaceae)-grassland ecosystem. Thesis. University of California, Riverside, California, USA.

Lodge, D. J. 1989. The influence of soil moisture and flooding on formation of VA-endo- and ectomycorrhizae in Populus and Salix. Plant Soil 117:243-253.

Lodge, D. J., and T. R. Wentworth. 1990. Negative associations among VA-mycorrhizal fungi and some ectomycorrhizal fungi inhabiting the same root system. Oikos 57:347-356.

Lutgen, E. R., D. Muir-Clairmont, J. Graham, and M. C. Rillig. 2003. Seasonality of arbuscular mycorrhizal hyphae and glomalin in a western Montana grassland. Plant and Soil 257:71-83.

McGonigle, T. P., M. H. Miller, D. G. Evans, G. L. Fairchild, and J. A. Swan. 1990. A new method which gives an objective measure of colonization of roots by vesicular arbuscular mycorrhizal fungi. New Phytologist 115:495-501.

Millard, P., M. Sommerkorn, and G. Grelet. 2007. Environmental change and carbon limitation in trees: a biochemical, ecophysiological and ecosystem appraisal. New Phytologist 175:11-28.

Millikin-Ishikawa, C. M., and C. S. Bledsoe. 2000. Seasonal and diurnal patterns of soil water potential in the rhizosphere of blue oaks: evidence for hydraulic lift. Oecologia 125:459465.

Parker, V. T., and C. H. Muller. 1982. Vegetational and environmental changes beneath isolated live oak trees 
(Quercus agrifolia) in a California annual grassland. American Midland Naturalist 107:69-81.

Peter, M., F. Ayer, and S. Egli. 2001. Nitrogen addition in a Norway spruce stand altered macromycete sporocarp production and below-ground ectomycorrhizal species composition. New Phytologist 149:311-325.

Phillips, N. G., M. G. Ryan, B. J. Bond, N. G. McDowell, T. M. Hinckley, and J. Cermák. 2003. Reliance of stored water increases with tree size in three species in the Pacific Northwest. Tree Physiology 23:237-245.

Pigott, C. 1982. Survival of mycorrhiza formed by Cenococcum geophilum Fr. in dry soils. New Phytologist 92:513-517.

Querejeta, J. I., L. M. Egerton-Warburton, and M. F. Allen. 2003. Direct nocturnal water transfer from oaks to their mycorrhizal symbionts during severe soil drying. Oecologia 134:55-64.

Querejeta, J. I., L. M. Egerton-Warburton, and M. F. Allen. 2007. Hydraulic lift may buffer rhizosphere hyphae against the negative effects of severe soil drying in a California oak savanna. Soil Biology and Biochemistry 39:409-417.

Read, D. J. 1991. Mycorrhizas in ecosystems. Experientia 47: 376-391.

Read, D. J., and J. Pérez-Moreno. 2003. Mycorrhizas and nutrient cycling in ecosystems - a journey towards relevance? New Phytologist 157:475-492.

Runion, G. B., R. J. Mitchell, H. H. Rogers, S. A. Prior, and T. K. Counts. 1997. Effects of nitrogen and water limitation and elevated atmospheric $\mathrm{CO}_{2}$ on ectomycorrhiza of longleaf pine. New Phytologist 137:681-689.

Smith, C. J., B. S. Danilowicz, A. K. Clear, F. Costello, B. Wilson, and W. G. Meier. 2005. T-Align, a web-based tool for comparison of multiple terminal restriction fragment length polymorphism profiles. FEMS Microbiology Ecology $54: 375-380$

Smith, M. E., G. W. Douhan, and D. M. Rizzo. 2007. Ectomycorrhizal community structure in a xeric Quercus woodland based on rDNA sequence analysis of sporocarps and pooled roots. New Phytologist 174:847-863.

Smith, S. E., and D. J. Read. 1997. Mycorrhizal symbiosis. Second edition. Academic Press, New York, New York, USA.
Sun, Y. P., T. Unestam, S. D. Lucas, K. J. Johanson, L. Kenne, and R. Finlay. 1999. Exudation-reabsorption in a mycorrhizal fungus, the dynamic interface for interaction with soil and soil microorganisms. Mycorrhiza 9:137-144.

Swaty, R. L., R. J. Deckert, T. G. Whitham, and C. A. Gehring. 2004. Ectomycorrhizal abundance and community composition shifts with drought: predictions from tree rings. Ecology 85:1072-1084.

Swaty, R. L., C. A. Gehring, M. van Ert, T. C. Theimer, P. Keim, and T. G. Whitham. 1998. Temporal variation in temperature and rainfall differentially affects ectomycorrhizal colonization at two contrasting sites. New Phytologist 139:733-739.

Taylor, A. F. S. 2002. Fungal diversity in ectomycorrhizal communities: sampling effort and species detection. Plant and Soil 244:19-28.

Tennant, D. 1975. Test of a modified line intersect method of estimating root length. Journal of Ecology 63:995-1001.

Titus, J. H., P. J. Titus, R. S. Nowak, and S. D. Smith. 2002. Arbuscular mycorrhizae of Mojave Desert plants. Western North American Naturalist 62:327-334.

Tu, K. P., P. D. Brooks, and T. E. Dawson. 2001. Using septum-capped vials with continuous-flow isotope ratio mass spectrometric analysis of atmospheric $\mathrm{CO}_{2}$ for Keeling plot applications. Rapid Communications in Mass Spectrometry 15:952-956.

Valdés, M., H. Asbjornsen, M. Gomez-Cardenas, M. Juarez, and K. A. Vogt. 2006. Drought effects on fine-root and ectomycorrhizal-root biomass in managed Pinus oaxaca Mirov stands in Oaxaca, Mexico. Mycorrhiza 16:117-124.

Van der Heijden, E. W., and T. W. Kuyper. 2001. Laboratory experiments imply the conditionality of mycorrhizal benefits for Salix repens: role of $\mathrm{pH}$ and nitrogen to phosphorus ratios. Plant and Soil 228:275-290.

Watson, G. W., K. G. Von Der Heide-Spravka, and K. V. Howe. 1990. Ecological significance of endo-/ectomycorrhizae in the oaks sub-genus Erythrobalanus. Arboricultural Journal 14:107-116.

Williams, A. F., and D. P. Rodoni. 1997. Regional isotope effects and application to hydrologic investigations in southwestern California. Water Resources Research 33: $1721-1729$. 